\title{
Horseshoe Kidney: A Fusion Anomaly
}

\section{Rishi Pokhrel, Ajaya Jang Kunwar, Isabela Thapa, Poonam Singh, Samrat Sapkota, Shailesh Adhikari and Trilok Pati Thapa}

Department of Anatomy, College of Medicine, Nepalese Army Institute of Health Sciences, Kathmandu, Nepal

ABSTRACT
A horseshoe shaped kidney was found in an approximately 35 years old female cadaver during routine
dissection at anatomy lab of our department. Further careful dissection was done in situ and ureter and
related blood vessels were identified and painted for identification.
The isthmus connecting the inferior poles of the kidneys was ventral to the great abdominal vessels. There
were multiple vessels supplying the horseshoe kidney on either side, the ureteric drainage pattern was also
not symmetrical.
Horseshoe kidney is the commonest renal fusion anomaly found in one in $400-600$ individuals, it is twice
common in males than females. It occurs when kidneys are pushed too close to each other during their
relative ascent through arterial fork of umbilical arteries in fetal life.
Horseshoe kidney is associated with increased risk of renal calculus. Surgical division of the isthmus
improves the renal function even in the absence of any pathology. Due to vascular variations,
Angiographyor CT scanning with vascular reconstruction is very helpful when planning surgery on
horseshoe kidney.

Correspondence: Rishi Pokhrel, Department of Anatomy, College of Medicine, Nepalese Army Institute of Health Sciences, Kathmandu, Nepal. Email: rongon28us@yahoo.com

DOI: http://dx.doi.org/10.3126/mjsbh.v17i1.19585

Submitted on: 2018-04-07

Accepted on: 2018-04-22

\section{CASE REPORT}

During routine dissection carried out for second year medical undergraduates, a horseshoe shaped kidney was discovered. The cadaver belonged to an approximately 35-year-old female. Further careful dissection was carried out in-situ to study the pattern of ureter, related blood vessels and presence of other anomalies. Related structures were painted using color-coded paints (red for artery, blue for vein and yellow for ureter) for easy identification.

Horseshoe kidney extended from vertebral level L2 to L4 with isthmus connecting the inferior poles, 


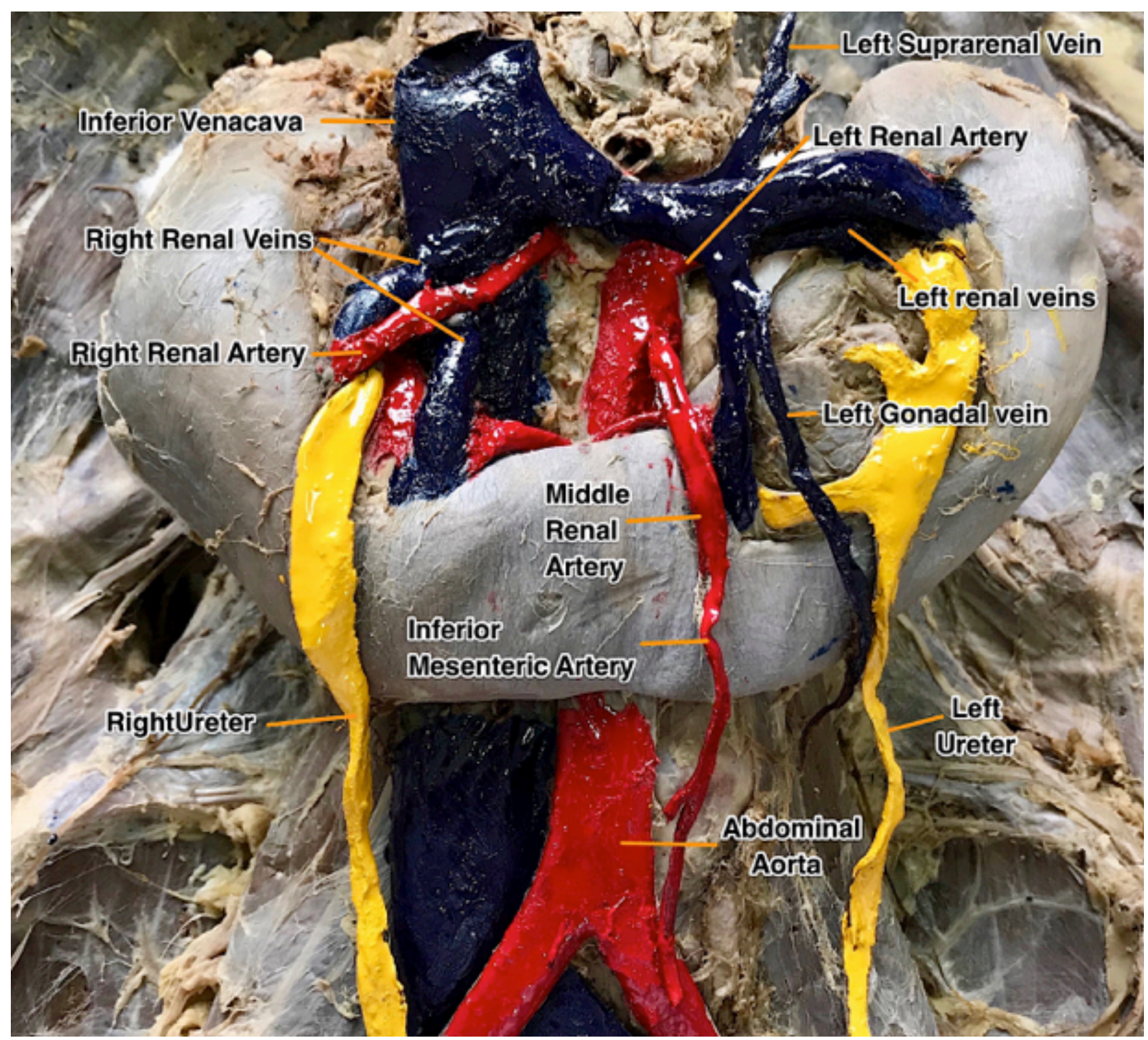

Figure 1: Dissected specimen of horseshoe kidney

ventral to abdominal aorta and inferior venacava (figure 1). Maximum transverse length was $17 \mathrm{~cm}$ and vertical diameter varied from 4.5 to $6 \mathrm{~cm}$. Maximum circumferential length was $33 \mathrm{~cm}$.

Multiple veins drained horseshoe kidney on either side; all veins drained into inferior venacava. Left suprarenal vein and left gonadal vein joined the left renal vein. Three renal arteries supplied the kidney. In addition to the usual left and right renal artery supplying each moiety, there was a middle renal artery arising from abdominal aorta dorsal to the isthmus (approximately L3 vertebral level). Middle renal artery divided one $\mathrm{cm}$ distal to its origin into two branches and the branches diverged laterally to enter the renal tissue. Ureters curved anterior to the isthmus with low insertion on right side. On left side three major calyxes were seen outside the renal tissue; each inserting at different levels of the left moiety.

\section{DISCUSSION AND REVIEW OF LITERATURE}

Horseshoe kidney; known by other names like en arcuatus, renal fusion or super kidney; is the most common renal fusion anomaly. It is found in 1 in 400 to 600 individuals 1,2 and is twice common in males. ${ }^{3}$ 'A transverse bridge of tissue, the isthmus, 
which usually but not always contains functioning renal substance, connects the two renal moieties. The isthmus connects the inferior poles, most commonly anterior to the great abdominal vessels. ${ }^{2}$ Vascular supply to horseshoe kidneys is variable. One vessel to each moiety is seen in $30 \%$ of cases, but multiple anomalous vessels, as seen in our case, are common. In view of this variable arterial anatomy, angiography or CT scanning with vascular reconstruction is very helpful when planning surgery on horseshoe kidneys. ${ }^{2}$

Embryologically, kidneys are formed at pelvis and later shift to more cranial abdominal position due to diminution of body curvature and growth in the lumbar and sacral regions. During their relative ascent, kidneys pass through the arterial fork formed by umbilical arteries. While doing so if kidneys are pushed too close together, their inferior poles may fuse to give rise to horseshoe kidneys. Position of horseshoe kidney is lower because its ascent is prevented by inferior mesenteric artery. ${ }^{1}$

Horseshoe kidney is vulnerable to obstruction and calculus disease ${ }^{4}$. The high rate of stone formation is probably secondary to infection and poor drainage from the renal pelvis. Surgical division of the isthmus improves the function of the kidneys whether there is any apparent pathology or not. ${ }^{5}$ Numerous other pathologies have been described in horseshoe kidney ${ }^{6-9}$ but correlation of causation of pathologies with this anomaly has not been established. ${ }^{10,11}$ Literature also describes numerous other anomalies associated with horseshoe kidney ${ }^{3}, 12$; in our case no other major anomaly was found. Prevalence of this anomaly in south Asian population has not been documented.

\section{CONCLUSIONS}

Horseshoe Horseshoe kidney is fusion anomaly of kidneys, not very uncommon and is present twice commonly in males than females. Usually discovered as incidental finding in radiological investigations, it increases the risk of renal calculi due to poor drainage but correlation with other renal pathologies including malignancies is not well established. The vasculature and drainage pattern of horseshoe kidney is variable and hence angiography or CT scanning with vascular reconstruction is helpful before planning any surgery in patients with this anomaly.

To cite this article: Pokhrel R, Kunwar AJ, Thapa I, Singh P, Sapkota S, Adhikari S, Thapa TP. Horseshoe Kidney: A Fusion Anomaly. MJSBH. 2018;17(1):49-52

Conflict of Interest: None declared

\section{REFERENCES}

1. Sadler TW. Langman's medical embryology: Lippincott Williams \& Wilkins; 2011.

2. Standring S. Gray's anatomy e-book: the anatomical basis of clinical practice: Elsevier Health Sciences; 2015.

3. Glodny B, Petersen J, Hofmann KJ, Schenk C, Herwig R, Trieb T, et al. Kidney fusion anomalies revisited: clinical and radiological analysis of 209 cases of crossed fused ectopia and horseshoe kidney. BJU international. 2009;103(2):224-35.

DOI: https://doi.org/10.1111/j.1464-410X.2008.07912.x 
4. Pitts Jr WR, Muecke EC. Horseshoe kidneys: a 40-year experience. The journal of Urology. 1975;113(6):743-6.

DOI: https://doi.org/10.1016/S0022-5347(17)59571-3

5. Rathore AH. Horse shoe kidney. JPMA The Journal of the Pakistan Medical Association. 1980;30(8): $178-81$.

6. De Vries JK. Hypernephroma, papilloma and stone: Occurring in horse-shoe kidney. The American Journal of Surgery. 1930;10(3):487-68.

DOI: https://doi.org/10.1016/S0002-9610(30)90678-2

7. Hohenfellner M, Schultz-Lampel D, Lampel A, Steinbach F, Cramer BM, Thüroff JW. Tumor in the horseshoe kidney: clinical implications and review of embryogenesis. The Journal of urology. 1992;147(4):1098-102.

DOI: https://doi.org/10.1016/S0022-5347(17)37486-4

8. Lambrianides AL, John DR. Medullary sponge disease in horseshoe kidney. Urology. 1987;29(4):426-7. DOI: https://doi.org/10.1016/0090-4295(87)90516-4

9. Murphy DM, Zincke H. Transitional cell carcinoma in the horseshoe kidney: report of 3 cases and review of the literature. BJU International. 1982;54(5):484-5.

DOI: https://doi.org/10.1111/j.1464-410X.1982.tb13570.x

10. Briones JR, Pareja RR, Martín FS, Toniolo GC, Pérez JH, Mavrich HV. Incidence of tumoural pathology in horseshoe kidneys. European urology. 1998;33(2):175-9.

DOI: https://doi.org/10.1159/000019551

11. Krishnan B, Truong LD, Saleh G, Sirbasku DM, Slawin KM. Horseshoe kidney is associated with an increased relative risk of primary renal carcinoid tumor. The Journal of urology. 1997;157(6):2059-66.

DOI: https://doi.org/10.1016/S0022-5347(01)64674-3

12. Boatman DL, Kölln CP, Flocks RH. Congenital anomalies associated with horseshoe kidney. The journal of urology. 1972;107(2):205-7

DOI: https://doi.org/10.1016/S0022-5347(17)60984-4 